\title{
PENERAPAN GAME EDUKASI "SPEAK ENGLISH" PADA SEKOLAH DASAR MENGGUNAKAN TEKNOLOGI SPEECH RECOGNITION
}

\author{
Ahmad Charisudin Ashar ${ }^{*}$, Munawarah.* , Agus Sifaunajah. ${ }^{* * *}$ \\ * Program Studi Teknik Informatika, Fakultas Teknologi Informasi, Universitas KH. A. Wahab Hasbullah
}

Correspondence Author: charis.ashar@gmail.com

\begin{tabular}{|c|c|}
\hline Info Artikel : & ABSTRACT \\
\hline \multirow[t]{2}{*}{$\begin{array}{l}\text { Keyword } \\
\text { Educational Game, } \\
\text { Speech } \\
\text { Recognition, } \\
\text { Android }\end{array}$} & $\begin{array}{l}\text { English is a language of communication was instrumental in conecting } \\
\text { between countries. Communicate can convey verbally or writing, so that } \\
\text { there is no misunderstanding in providing information. Many people from } \\
\text { various countries are encouraged to learn English as a means of adding an } \\
\text { insight in the development of the times. In Indonesia, English is a foreign } \\
\text { language that must be studied, starting from elementary school to university. } \\
\text { However, in the practice of learning there are still many problems, especially } \\
\text { in elementary school education institutions. Such as students have difficulty } \\
\text { in learning a foreign language or a new language that is only used when } \\
\text { learning in class, another problem is because the personal character of each } \\
\text { student is different in paying attention to the lesson. Learning methods also } \\
\text { need to be considered because there are still many students who are lacking } \\
\text { in utilizing learning media, especially learning media presented in android- } \\
\text { based smartphones. This study aims to create an educational game that } \\
\text { contains English learning using Speech Recognition technology at the } \\
\text { Elementary School. The method used is the System Development Life Cycle } \\
\text { (SDLC) using the Waterfall model. In the process of data collection, } \\
\text { researchers used a study of literature and observation at MI AL IHSAN } \\
\text { Jombang. The results showed that educational gam helps students more } \\
\text { effectively and can encourage students in learning English. }\end{array}$ \\
\hline & INTISARI \\
\hline $\begin{array}{l}\text { Kata Kunci : } \\
\text { Game Edukasi, , } \\
\text { Speech } \\
\text { Recognition, } \\
\text { Adroid }\end{array}$ & $\begin{array}{l}\text { Bahasa inggris merupakan sebuah bahasa komunikasi yang sangat berperan } \\
\text { dalam menghubungkan antar negara. Dalam berkomunikasi dapat } \\
\text { menyampaikan secara lisan maupun tulisan agar tidak terjadi } \\
\text { kesalahpahaman dalam memberikan informasi. Orang-orang dari berbagai } \\
\text { negara terdorong untuk mempelajari bahasa inggris sebagai sarana } \\
\text { menambah wawasan dalam mengikuti perkembangan zaman. Di Indonesia } \\
\text { sendiri, bahasa Inggris merupakan bahasa asing yang wajib untuk dipelajari, } \\
\text { mulai dari tingkat Sekolah Dasar sampai Perguruan Tinggi. Akan tetapi } \\
\text { dalam praktek pembelajarannya masih terdapat banyak masalah, Khususnya } \\
\text { di lembaga pendidikan tingkat Sekolah Dasar. Masalah tersebut seperti, siswa } \\
\text { kesulitan dalam mempelajari bahasa asing atau bahasa baru yang hanya } \\
\text { digunakan ketika proses belajar di kelas, masalah lain disebabkan karakter } \\
\text { pribadi masing-masing siswa berbeda-beda dalam memperhatikan pelajaran. } \\
\text { Metode pembelajaran juga perlu dipertimbangkan karena masih banyak siswa } \\
\text { yang kurang dalam memanfaatkan media pembelajaran, terutama media } \\
\text { pembelajaran yang disajikan dalam smartphone berbasis android. Penelitian } \\
\text { ini bertujuan untuk membuat game edukasi yang berisi pembelajaran bahasa } \\
\text { inggris dengan menggunakan teknologi Speech Recognition pada tingkat } \\
\text { Sekolah Dasar. Metode yang digunakan yaitu System Development Life Cycle } \\
\text { (SDLC) dengan menggunakan model Waterfall. Dalam proses pengumpulan }\end{array}$ \\
\hline
\end{tabular}




\begin{tabular}{|l|l|}
\hline & $\begin{array}{l}\text { data, peneliti menggunakan study literatur dan observasi di MI AL IHSAN } \\
\text { Jombang. Hasil penelitian menunjukkan bahwa game yang edukatif sangat } \\
\text { membantu siswa lebih efektif dan dapat mendorong siswa dalam mempelajari } \\
\text { bahasa inggris. }\end{array}$ \\
\hline
\end{tabular}

\section{PENDAHULUAN}

Bahasa inggris merupakan sebuah bahasa komunikasi yang sering digunakan antar negara secara lisan maupun tulisan dalam memberikan informasi. Orang-orang dari berbagai negara terdorong untuk mempelajari bahasa inggris sebagai sarana menambah wawasan dalam mengikuti perkembangan zaman. Di Indonesia sendiri, bahasa Inggris merupakan bahasa asing yang wajib untuk dipelajari, mulai dari tingkat Sekolah Dasar sampai Perguruan Tinggi. Akan tetapi dalam praktek pembelajarannya masih terdapat banyak masalah, Khususnya di lembaga pendidikan tingkat Sekolah Dasar. Masalah tersebut seperti, siswa kesulitan dalam mempelajari bahasa asing atau bahasa baru yang hanya digunakan ketika proses belajar di kelas, masalah lain disebabkan karakter pribadi masing-masing siswa berbeda-beda dalam memperhatikan pelajaran. Metode pembelajaran juga perlu dipertimbangkan karena masih banyak siswa yang kurang dalam memanfaatkan media pembelajaran, terutama media pembelajaran yang disajikan dalam smartphone berbasis android

Seiring berkembangnya teknologi smartphone dengan berbagai macam sistem operasi. Seharusnya bisa dimanfaatkan dengan tepat untuk membantu dan memudahkan dalam berbagai hal terutama dalam hal belajar. Sistem operasi paling populer yang digunakan para pengembang adalah android. Dengan sistem operasi tersebut, setiap hal yang berhubungan dengan teknologi dapat dibuat menjadi lebih praktis dan menarik di dalam smartphone. Salah satunya adalah dalam dunia pendidikan, seperti materi pelajaran bahasa inggris yang disajikan dalam bentuk aplikasi. Dengan adanya aplikasi dapat membantu siswa dalam mempelajari bahasa inggris secara langsung dengan mengakses materi di dalam aplikasi melalui smartphone dimanapun dan kapanpun. Namun dalam merancang aplikasi perlu melibatkan unsur edukasi (education) dengan hiburan (entertainment), agar siswa tidak hanya mendapat materi pembelajaran, tetapi juga dapat bermain untuk menguji kemampuan dalam menguasai materi pembelajaran dalam media. Menurut Jurnal yang ditulis Randle, dkk (2015, h.65) "Games Are activities of interest to every individual both adult and children. Games are used to learn skills, prepare for tactical activities such as military training and give individuals the ability to compete against each other. Computer games are an aspect of machine learning, other aspect of Artifical Intelegence ( AI )

Berkaitan penjelasan latar belakang di atas, dapat disimpulkan bahwa perlu adanya sebuah media pembelajaran bahasa inggris yang mencakup dua fungsi yakni media edukasi sebagai sarana pembelajaran dan permainan sebagai sarana bermain sambil mengasah kemampuan. Oleh karena itu, peneliti terdorong untuk merancang sebuah aplikasi yang dapat menjadi media pembelajaran alternatif di bidang mata pelajaran bahasa inggris. Aplikasi tersebut berjudul Game Edukasi "Speak English"dengan Menggunakan Teknologi Speech Recognition. Aplikasi game ini menampilkan gambar dikombinasikan dengan teks dan audio. Fungsi teknologi Speech Recognition (pengenalan suara) sebagai output suara dari aplikasi untuk didengarkan pengguna dan menerima input suara yang diucapkan pengguna. Kemudian disesuaikan dengan kata dan gambar yang ditampilkan. Apabila pola suara dan kata sama ataupun tidak, aplikasi akan memberikan respon. 


\section{KAJIAN TEORI}

a. Game Edukasi

Game edukasi adalah sebuah alat bantu belajar berbentuk game digital yang dirancang sebagai sarana belajar sambil bermain menggunakan teknologi multimedia interaktif. Menurut Widiastuti dan Setiawan yang mengutip Hurd dan Jenuings dalam merancang game edukasi terdapat beberapa kriteria (Jayanegara 2015). yaitu:

1. Nilai Keseluruhan (Overall Value)

2. Dapat Digunakan (Usability)

3. Keakuratan (Accuracy)

4. Kesesuaian (Appropriateness)

5. Relevan (Relevance)

6. Objektifitas (Objectives)

7. Umpan Balik (Feedback)

b. Android

Android adalah salah satu sistem operasi berbasis linux yang dirilis oleh Google Inc untuk perangkat telepon seluler seperti smartphone dan komputer tablet. Android sangat populer di kalangan para pengembang saat ini, dimana android menyediakan platform yang terbuka (open source) untuk menciptakan dan mengembangkan aplikasi mereka sendiri (damayanti, 2017)

\section{c. Speech Recognition}

Speech Recognition (Pengenalan ucapan) adalah pengembangan teknik dan sistem yang memungkinkan komputer untuk menerima masukan dalam bentuk katakata yang diucapkan. Teknologi ini memungkinkan perangkat untuk mengenali dan memahami kata-kata yang diucapkan dengan mendigitalkan kata-kata dan mencocokkan sinyal digital dengan pola tertentu yang tersimpan dalam perangkat. Kata-kata yang diucapkan diubah menjadi sinyal digital dengan mengubah gelombang suara menjadi serangkaian angka yang kemudian disesuaikan dengan kode khusus untuk mengidentifikasi kata-kata. Hasil identifikasi kata-kata yang diucapkan dapat ditampilkan dalam bentuk teks atau dapat dibaca oleh teknologi perangkat sebagai perintah untuk melakukan suatu pekerjaan, misalnya, menekan tombol pada handset yang dilakukan secara otomatis oleh perintah suara. (Hugeng 2015).

d. Hidden Markov Model

Hidden Markov Model (HMM) adalah model statistik dari suatu sistem yang diasumsikan sebagai markov proses dengan state yang tidak diketahui. State yang tersembunyi harus ditentukan dari state bagian yang dapat diamati. Kemudian, state yang ditentukan dapat digunakan untuk analisis lebih lanjut, misalnya, untuk pengenalan pola. Dalam HMM, suatu state tidak dapat diamati secara langsung, tetapi dapat diamati parameter-parameter yang dipengaruhi oleh state. Setiap state memiliki distribusi probabilitas atas output yang mungkin muncul. Oleh karena itu, serangkaian output yang dihasilkan oleh HMM memberikan beberapa informasi tentang urutan state. (Hugeng, 2015).

\section{METODE PENELITIAN}

\section{a. Analisis Sistem}

Analisis sistem ini menjelaskan tentang kebutuhan sistem yang diperlukan dalam membuat game Speak English, kebutuhan sistem tersebut sebagai berikut.

1. Kebutuhan Fungsional

Adapun kebutuhan fungsional sebagai berikut: 
- Sistem berisi materi pembelajaran bahasa inggris yang menitikberatkan pada keterampilan berbicara (speaking) dan mendengarkan (listening)

- Sistem berisi konten yang sesuai dengan materi pembelajaran yang ada dan dibuat dengan menarik agar pengguna tidak cepat bosan

- Sistem meyajikan permainan berdasarkan materi yang dibagi menjadi beberapa level.

- Sistem menyajikan sebuah interaksi penyampaian materi terhadap pengguna.

2. Kebutuhan Non Fungsional

Adapun kebutuhan non fungsional sebagai berikut :

- Kebutuhan Perangkat Keras

Perangkat

RAM

Layar
: Smartphone Android

: Minimum 512MB

: LCD Touchscreen

- Kebutuhan Perangkat Lunak

Sistem operasi PC : Windows 10

Sistem operasi Smartphone : Android 4.4.2 Kitkat

Tools game

: Construc 2

Tool pendukung

: CorelDraw7, AudaCity, FL Studio,

b. Perancangan sistem

Perancangan sistem ini menggunakan perancangan sistem usecase diagram, activity diagram, dan flowchart diagram. Desain perancangan ini juga merupakan alat bantu dalam memahami alur kerja sistem dan sebagai sarana pemecahan suatu masalah secara logika.

1. Flowchart Sistem

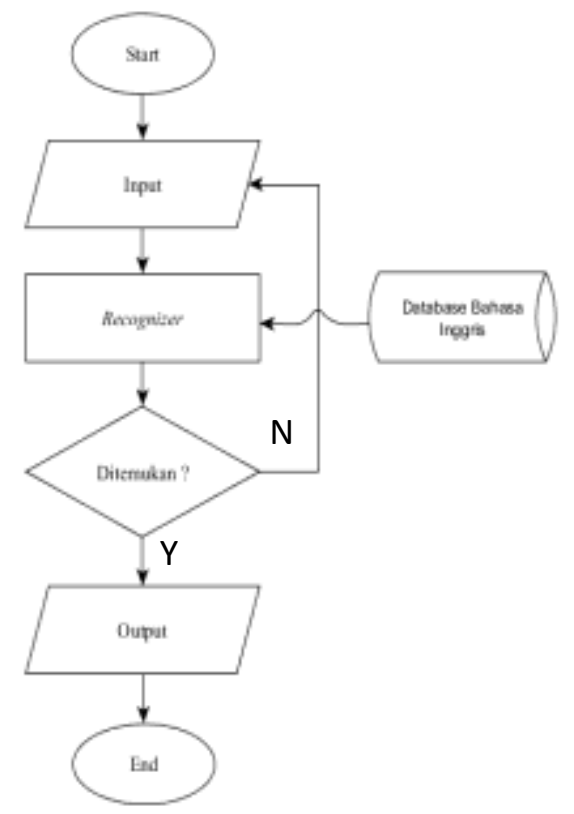

Gambar 1. Flowchart konversi suara menjadi teks

Proses dalam menjalankan game ini yakni pertama-tama pengguna harus menekan gambar sesuai perintah game. Kemudian pengguna mengucapkan kata 
dengan menggunakan bahasa inggris. Setelah itu, block recognizer akan melakukan proses recognition dan mengubah suara menjadi teks. Di bawah ini adalah diagram alur block recognizer :

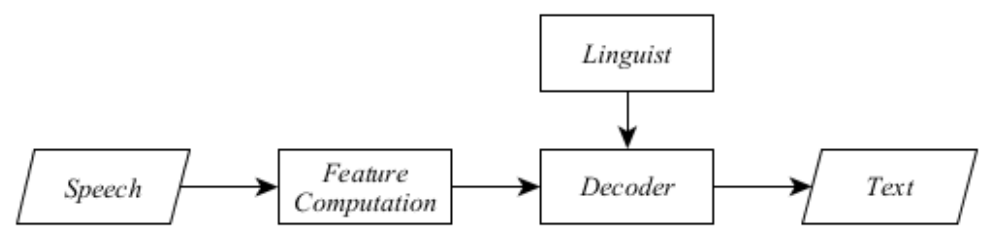

Gambar 2. Diagram alur Block Recognizer

Beberapa fungsi yang terdapat pada Diagram alur Block Recognizer, antara lain

1. Feature Computation

Berfungsi sebagai pengubah bentuk gelombang suara menjadi kode-kode unik untuk digunakan dalam proses pengenalan suara.

2. Decoder

Decoder merupakan bagian inti dari pengenal suara

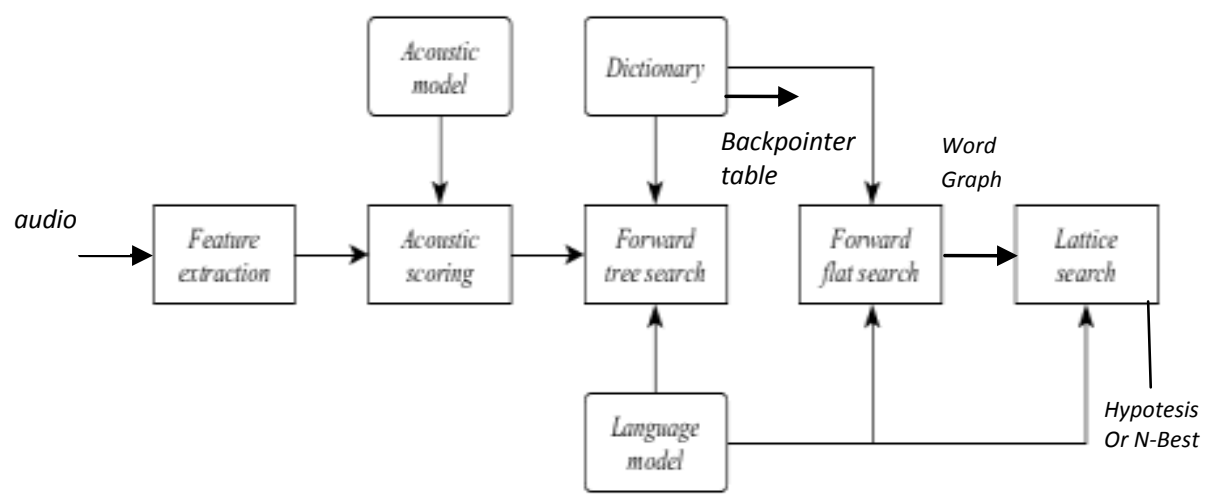

Gambar 3. Diagram alur Block Decoder

Gambar di atas merupakan keseluruhan proses decoding. Secara sederhana proses tersebut dapat dilihat pada gambar berikut ini : 


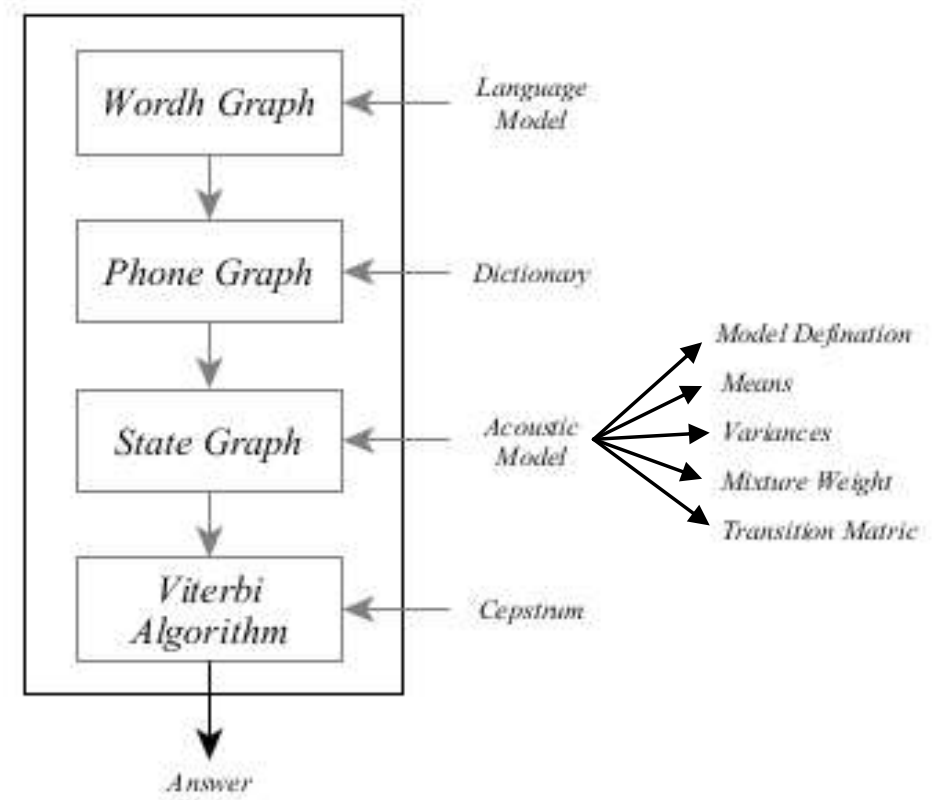

Gambar 4 Penggunaan Resource oleh Decoder

Alur dari decoding secara umum sebagai berikut :

- Word Graph

Merupakan graf dari kata yang dinyatakan sebagai graf yang diberi tabel dan mempresentasikan grammar dimana tiap node (titik) terdiri dari 1 kata saja.

- Phone Graph

Phone Graph yang tiap nodenya mempresentasikan fenom dari kata dan nanrinya akan menentukan kecenderungan suatu fenom berpindah ke fenom lain sesuai node.

- State Graph

State Graph merupakan graf yang menandakan kondisi.

- Viterbi Algoritm

Sebuah metode decoding untuk mengkodekan kembali bit yang telah dikodekan oleh convolutional code dengan prinsip mencari kemungkinan bit yang paling mirip atau dapat disebut maximum likelihood. Proses decoding dapat disamakan dengan membandingkan deretan bit yang diterima dengan semua kemungkinan bit berkode. Dari proses perbandingan tersebut, akan dipilih bit yang paling mirip antara deretan yang diterima dengan kemungkinan deretan bit-bit yang ada.

3. Linguistic

Linguist terdiri dari 3 buah komponen utama, antara lain :

- Language Model

Language Model berperan merepresentasikan urutan kata yang valid fan paling masuk akal. Implementasi dari model ini mendukung berbaga format.

- Dictionary 
Modul ini berperan menyediakan pronounciations atau pelafalan untuk kata-kata yang ada dalam language model. Pengucapan memecah kata menjadi urutan unit sub-kata yang ditemukan pada model akustik

- Acoustic Model

Model accoustic berperan menyediakan pemetaan anatara unit ucapan (speech) dan HMM, di dalam nilainanya dapat dicocokkan dengan hasil ekstraksi ciri yang disediakan oleh bagian front-end. Secara keseluruhan, bagian lingusit menghasilkan search graph yang digunakan oleh decoder selama pencarian

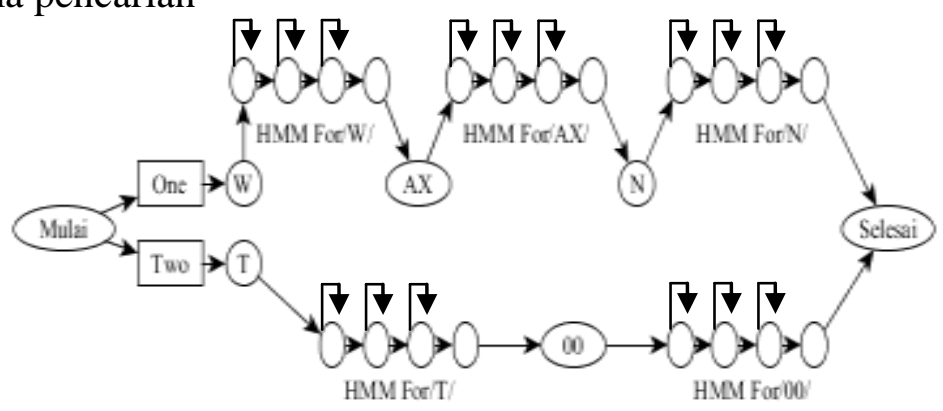

Gambar 5. Search Graph

Search graph berupa direct graph. Masing-masing state (kondisi) mempresentasikan komponen dari bagian linguist. Misal seperti pengucapan kata "one" and "two" merupakan bagian dari language model. Pecahan kata pada lingkatan berwarna hitam merupakan bagian dari Dictionary dan bagian HM mencerminkan acoustic model.

Pada tahap ini akan dibangun model HMM untuk setiap kata yang digunakan. Diawali dengan inisialisasi model HMM dengan jumlah state = ntaste. Model ini memiliki arsitektur left to right model. Dengan parameter awal model tersebut ditentukan dengan nilai awal yang sama untuk setiap model. Berikut merupakan alur proses pelatihan model HMM :

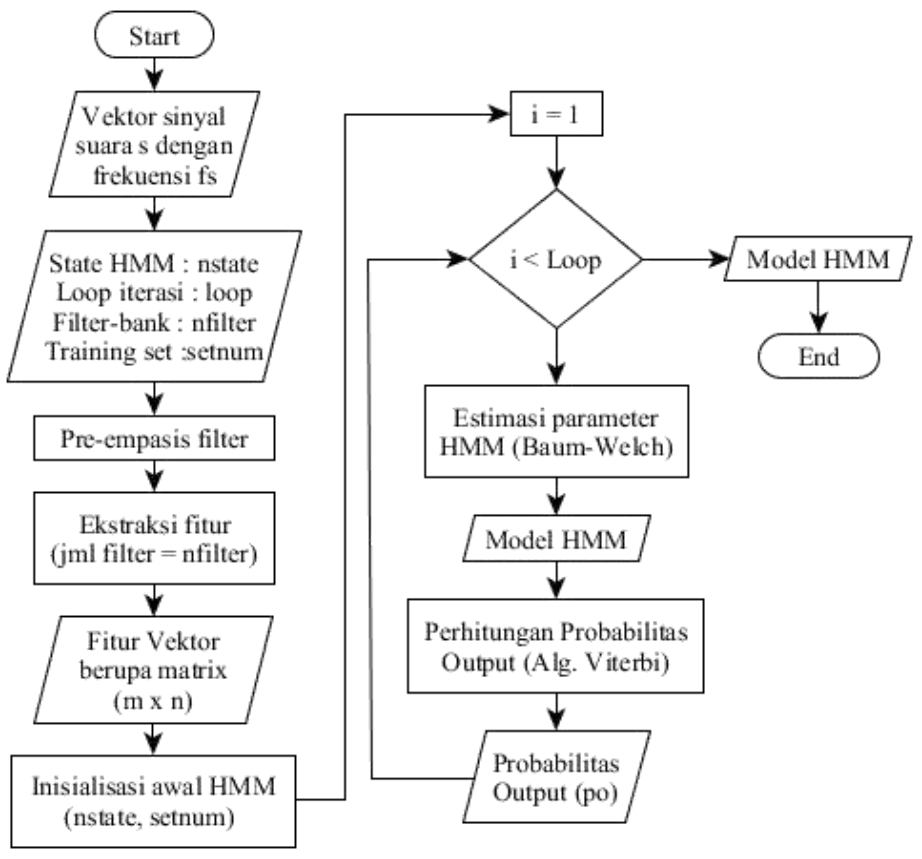

Gambar 6. Flowchart proses HMM 
Pelatihan model tersebut untuk mendapatkan nilai parameter yang optimal sesuai dengan yang digunakan. Proses pelatihan ini akan dilakukan sebanyak loop kali. Dalam proses pelatihan tersebut, akan dilakukan re-estimasi parameter. Kemudian akan menghasilkan sebuah model HMM

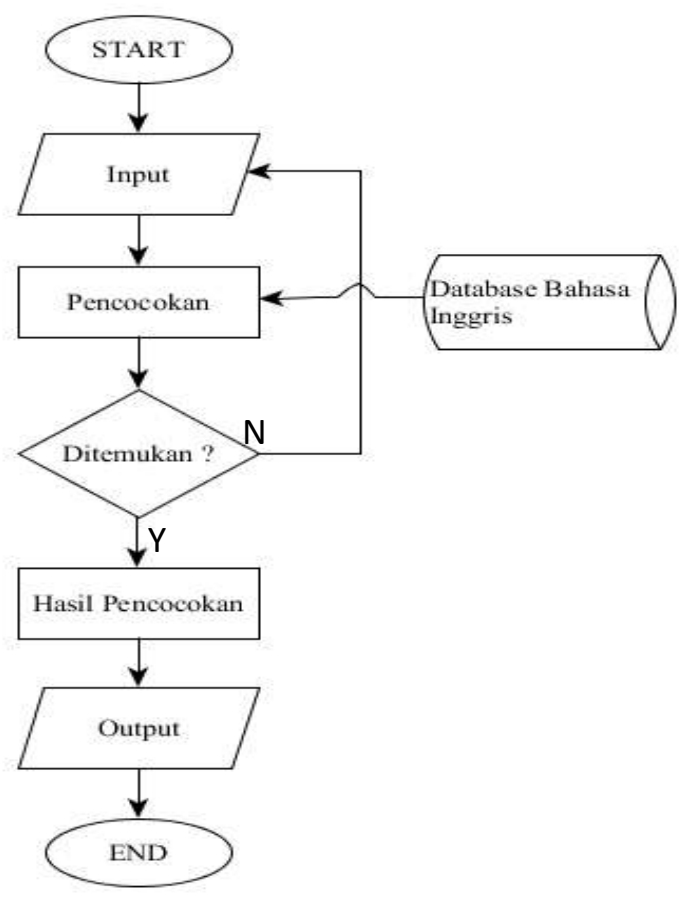

\section{Gambar 7. Flowchart Proses Pencocokan}

Pada game ini, selain dapat melakukan konversi dari suara kemudian di ubah menjadi teks kemudian sistem juga akan mencocokkan hasil konversi suara menjadi teks dalam bahasa inggris dengan memanfaatkan Google API.

2. Usecase Diagram

Desain menggunakan usecase diagram berfungsi untuk menggambarkan fungsi-fungsi apa saja yang ada pada aplikasi. Selain itu juga berfungsi untuk mengetahui fitur-fitur yang ada pada game yang akan dibuat. Adapun usecase sistem yang akan dirancang sebagai berikut :

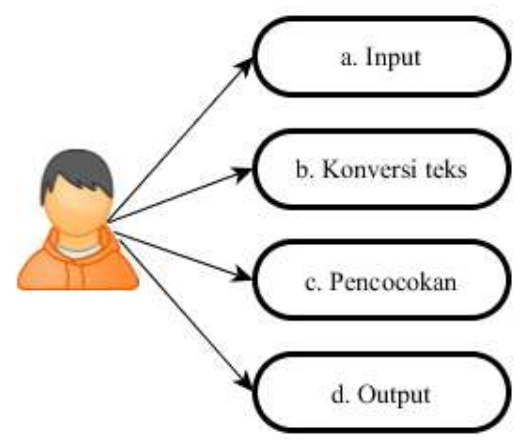

Gambar 8. Usecase diagram game 
Pada Gambar 8. dapat dijelaskan bahwa pada game yang akan dibangun, pengguna dapat menggunakan 4 fungsi yang ada di dalam game, yaitu :

1. Input

Merupakan fungsi menerima input berupa suara pengucapan kata dari pengguna.

2. Konversi teks

Merupakan fungsi yang dapat menjadikan suara yang telah di konversi menjadi sebuah teks.

3. Pencocokan

Merupakan fungsi yang mencocokkan kata dari hasil konversi teks dengan database Google API secara online.

4. Output

Merupakan hasil dari pencocokkan kata dari hasil konversi teks dengan database Google API secara online. jika hasilnya sama, berarti proses berhasil.

\section{HASIL DAN PEMBAHASAN}

Dibagian ini peniliti akan membahas beberapa hal yang terkait dari pembuatan game Speak English, yaitu meliputi antarmuka (interface) dan Data base.

1. Antarmuka (Interface)

Antarmuka (interface) dalam game Speak English terdapat beberapa bagian, yaitu halaman utama, konten atau isi dan pop up.

a. Halaman Utama

Halaman utama game merupakan halaman yang akan tampil ketika pengguna membuka aplikasi ini. Halaman utama terdapat 2 menu utama yaitu menu belajar dan menu bermain

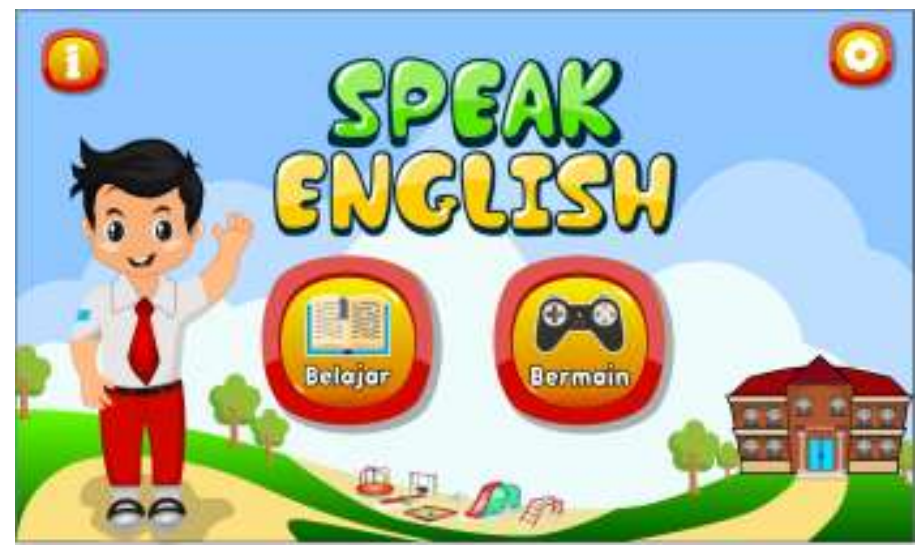

b. Konten atau Isi

Gambar 9. Tampilan halaman utama

Pada bagian konten atau isi terdapat tampilan yang berhubungan dengan isi dari menu utama, diantaranya sebagai berikut :

- Pada menu belajar berisi konten pembelajaran bahasa inggris yang dikelompokkan menjadi 3 materi, yaitu materi 1, materi 2 dan meateri 3 . 


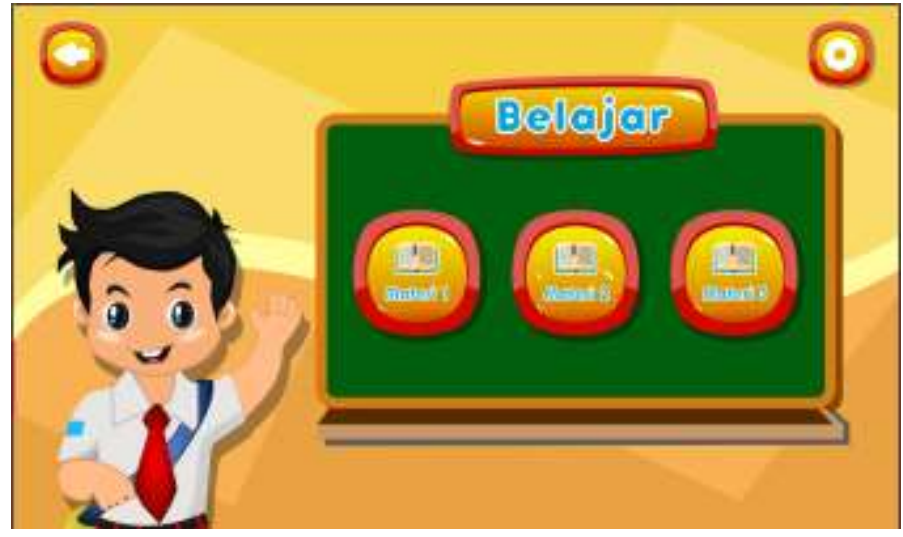

Gambar 10. Tampilan menu belajar

Setiap materi berisi kategori kata yang dapat pengguna pelajari

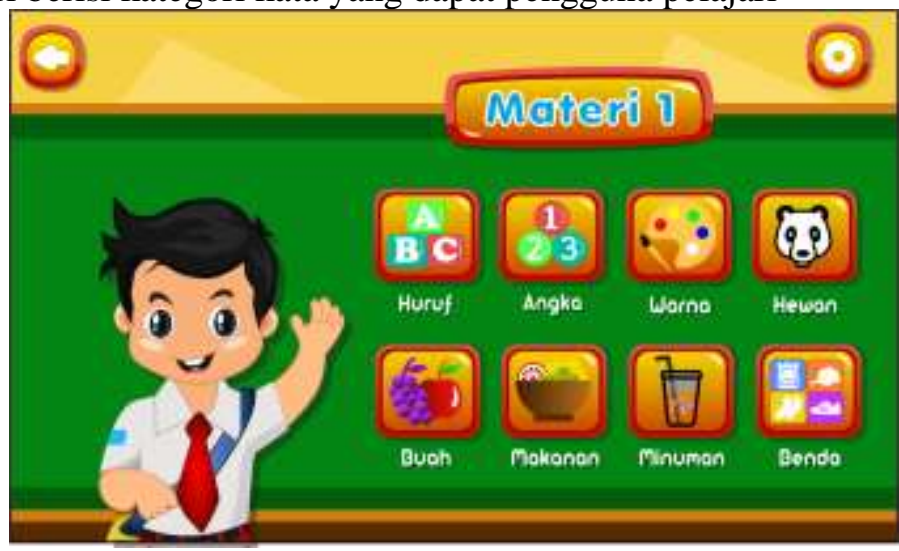

Gambar 11. Tampilan menu materi

- Pada menu bermain berisi konten permainan tebak kata yang dikelompokkan menjadi 3 tingkatan yaitu mudah, sedang dan sulit

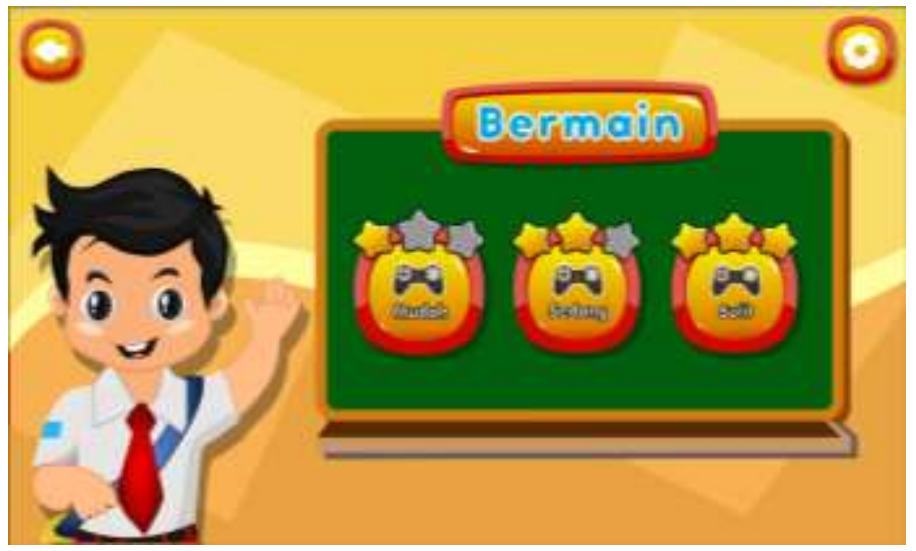

Gambar 12. Tampilan menu bermain

Setiap tingkatan berisi 5 sub tingkatan, sehingga total tingkatan yang harus diselesaikan berjumlah 15 tingkatan. 
c. Proses Berlajar

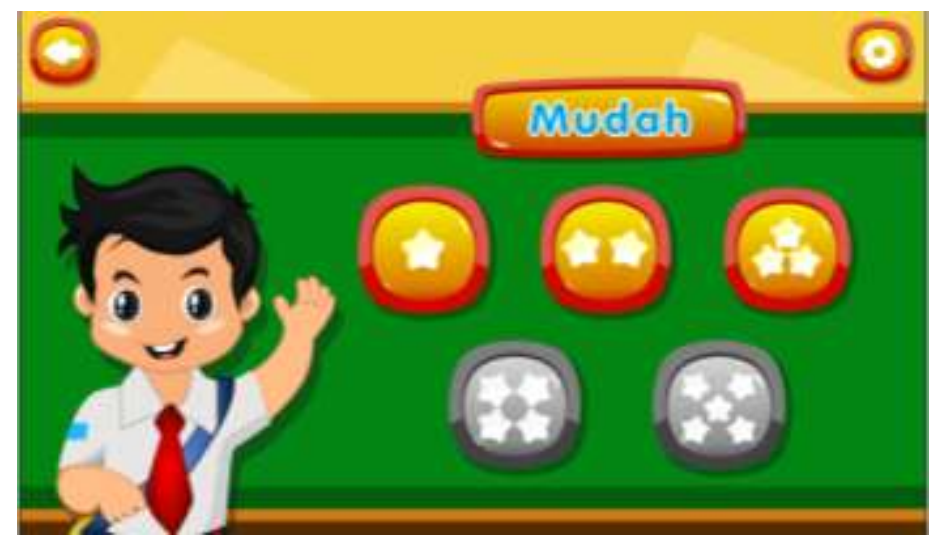

Gambar 13. Tampilan menu tingkatan

Bagian ini pengguna dapat mendengarkan (listening) kata dengan menyentuh (touch) gambar yang tampil pada box gambar. Pengguna juga dapat memainkan secara berulangkali atau melanjutkan gambar berikutnya.

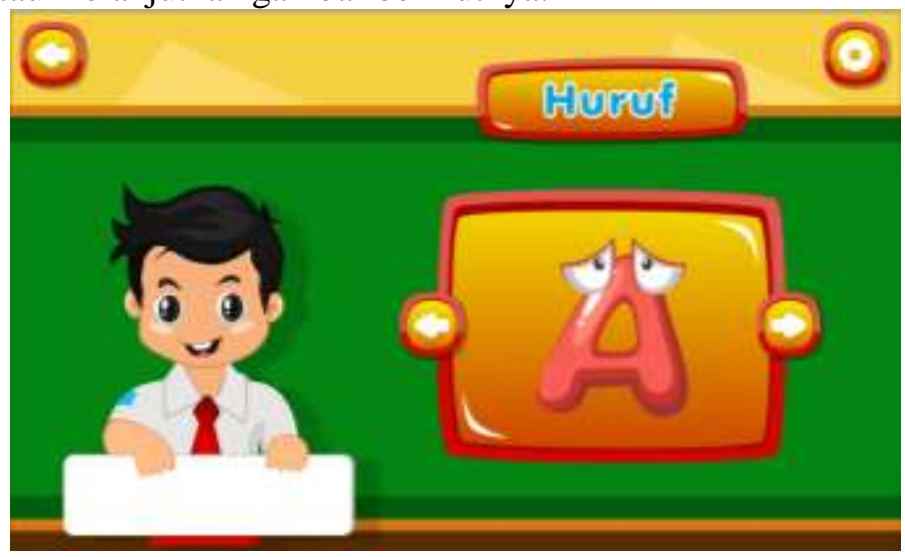

Gambar 14. Tampilan menu output suara

d. Proses Bermain

Pada bagian ini pengguna dapat menekan ikon speaker, setelah itu pengguna dapat menjawab dan menebak dengan mengucapkan kata sesuai gambar yang tampil selama durasi 5 detik.

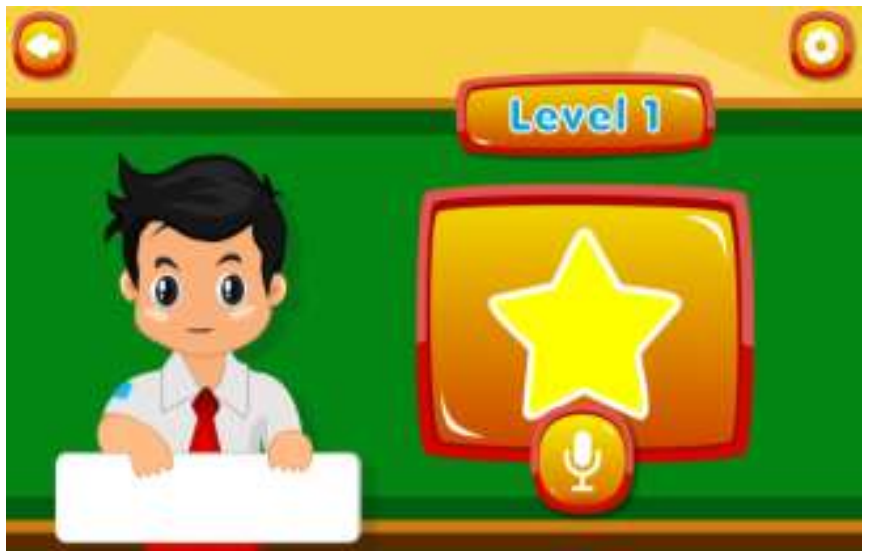

e. $\quad$ Pop Up

Gambar 15. Tampilan menu input suara

Panel ini akan muncul setiap pengguna berhasil menyelesaikan 1 sub tingkatan bermain. 


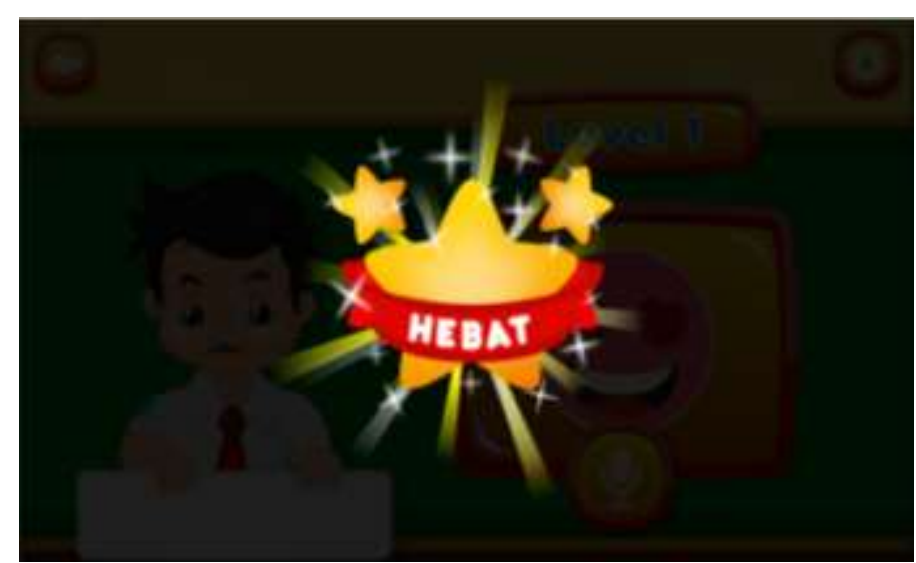

Gambar 16. Tampilan pop up

2. Basis Data (Database)

Data base penyimpanan konten bermain ini berisi konten yang di acak dan dipilah dari tingkatan pengucapan kata yang mudah sampai tingkatan pengucapan yang sulit. Berikut tabel data base penyimpanan konten bermain

Tabel 1. Daftar konten bermain

\begin{tabular}{|r|l|}
\hline $\mathbf{X}$ & Data \\
\hline $\mathbf{0}$ & Sing;Yellow;Happy;Sleeping;Playing; \\
\hline $\mathbf{1}$ & Green;Monday;E;Blue;Smile; \\
\hline $\mathbf{2}$ & Cry;D;Pink;Angry;5; \\
\hline $\mathbf{3}$ & Good Morning;January;A;1;Watching; \\
\hline $\mathbf{4}$ & Good Afternoon;February;December;C;Wednesday; \\
\hline $\mathbf{5}$ & Good Evening;Breakfast;2;3;March; \\
\hline $\mathbf{6}$ & Good Night;Thank You;Tuesday;August;Dancing; \\
\hline $\mathbf{7}$ & Friday;Thursday;paint;Laugh;4; \\
\hline $\mathbf{8}$ & B;Bath;Red;Reading;Writing; \\
\hline
\end{tabular}

\section{KESIMPULAN}

Berdasarkan hasil penelitian selama perancangan, implementasi, dan proses uji coba perangkat lunak yang sudah dilakukan. Peneliti mengambil kesimpulan dari uji coba game Speak English dengan menggunakan teknologi speech recognition sebagai berikut :

1. Game Speak English ini memanfaatkan suara pengguna sebagai masukan (input) yang dikonversi menjadi teks bahasa inggris kemudian diproses pencocokan kata dengan teknologi speech recognition secara online.

2. Setelah diuji coba dengan menggunakan 45 kata yang berbeda, didapatkan hasil dengan presentase $93 \%$.

3. Hasil observasi menunjukkan bahwa bahwa game yang edukatif sangat membantu siswa lebih efektif dan dapat mendorong siswa dalam mempelajari bahasa inggris. 


\section{DAFTAR PUSTAKA}

Damayanti Ayu, Wahyu Hidayat, Eka Widhi Yunarso. "Aplikasi Pembelajaran Bahasa Inggris Untuk Kelas 4 Sd (Studi Kasus: Sdn Cimahi Mandiri 2)”. eProceeding of Applied Science Universitas Telkom, Vol. 3, No. 3, Desember 2017, hal. 1216, ISSN 2442-5826

Hugeng Hugeng, Edbert Hansel. "Implementation of Android Based Speech Recognition for Indonesian Geography Dictionary". Ultima Computing Jurnal Sistem Komputer Universitas Multimedia Nusantara (UMN) Jakarta, Vol. 7, No. 2, Desember 2015, hal. 76-82, ISSN 2355-3286

Jayanegara I Nyoman, S.Sn., M,Sn - I WayanAdi Putra Yasa, S.Kom. "Perancangan Game Jalak Bali Berbasis Android". JANAPATI (Jurnal Nasional Pendidikan Teknik Informatika) Universitas Pendidikan Ganesha Singaraja-Bali, Vol. 4, No. 1, Maret 2015, hal. 20-30, ISSN 2087-2658

M. Fikri Shinwani, Rancang Bangun Aplikasi Voice Translator Berbasis Android menggunakan Hidden Markov Model. Skripsi, Universitas Islam Negeri Maulana Malik Ibrahim Malang, Tahun 2016

Pingge Heronimus Delu, Muhammad Nur Wangid. "Faktor Yang Mempengaruhi Hasil Belajar Siswa Sekolah Dasar Di Kecamatan Kota Tambolaka". JPSD (Jurnal Pendidikan Sekolah Dasar) PGSD Universitas Ahmad Dahlan Yogyakarta, Vol. 2, No. 1, Desember 2016, hal. 148-167, ISSN : 2356-3869

Randle, O. A., Ogunduyile, O. O., \& Fashola, N. A. (2015). A Comparism of The Performance of Supervised and Unsupervised Machine Learning Techniques in Evolving Awale/Mancala/Ayo Game Player. International Journal of Game Theory and Technology (IJGTT), 1.

Tyaningsih, Annisa Rachmani. "Pembelajaran Bahasa Inggris Pada Anak Usia Dini Berbasis Proses Pemerolehan Bahasa Pertama". Unit Bahasa (UB) Sekolah Tinggi Pariwisata (STP) Bandung, Vol. 3, No. 1, Juli 2016, hal. 74-82, ISSN : 2336-1602 